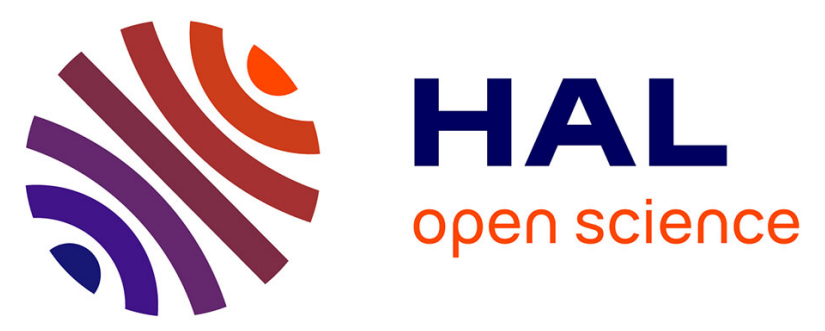

\title{
Characterizing Transformation Phenomena and Elastic Moduli of Austenite and Oriented Martensite of Superelastic Thin NiTi Wire through Isothermal Dynamic Mechanical Analysis
}

\author{
Thierry Alonso, Denis Favier, Grégory Chagnon
}

\section{To cite this version:}

Thierry Alonso, Denis Favier, Grégory Chagnon. Characterizing Transformation Phenomena and Elastic Moduli of Austenite and Oriented Martensite of Superelastic Thin NiTi Wire through Isothermal Dynamic Mechanical Analysis. Journal of Materials Engineering and Performance, 2019, 10.1007/s11665-019-04225-6 . hal-02195024

\section{HAL Id: hal-02195024 \\ https://hal.science/hal-02195024}

Submitted on 14 Apr 2020

HAL is a multi-disciplinary open access archive for the deposit and dissemination of scientific research documents, whether they are published or not. The documents may come from teaching and research institutions in France or abroad, or from public or private research centers.
L'archive ouverte pluridisciplinaire HAL, est destinée au dépôt et à la diffusion de documents scientifiques de niveau recherche, publiés ou non, émanant des établissements d'enseignement et de recherche français ou étrangers, des laboratoires publics ou privés. 


\title{
Characterizing transformation phenomena and elastic moduli of austenite and oriented martensite of superelastic thin NiTi wire through isothermal Dynamic Mechanical Analysis
}

\author{
Thierry Alonso, Denis Favier, Grégory Chagnon \\ Univ. Grenoble Alpes, CNRS, Grenoble INP, TIMC-IMAG, 38000 Grenoble, France
}

\begin{abstract}
In this paper, superelastic behavior of Nickel Titanium thin wires is characterized using the method of dynamic mechanical analysis. Nominal dynamic storage modulus $E^{\prime}$ is measured as function of nominal strain and stress during isothermal superelastic tensile tests at three testing temperatures above the reverse martensitic transformation finish temperature. The method brings new information on deformation mechanisms compared to the consideration of only tensile stress-strain curves. It is shown that determination of the elastic moduli $E$, especially at high strain, requires to calculate the true storage modulus $E_{t}^{\prime}$. Using $E_{t}^{\prime}$ and not $E^{\prime}$, elastic modulus of oriented martensite $E_{M}$ is determined equal to $73 \mathrm{GPa}$ of the same order than the elastic modulus of austenite $E_{A}$ equal to $70 \mathrm{GPa}$.

Two models are then proposed to simulate experimental storage moduli evolution during the tests. A first model explains the $E^{\prime}$ evolution during stress plateau by the localization phenomenon; it leads to express $E^{\prime}$ as function of the nominal strain. A second model describes the evolution of $E_{t}^{\prime}$ after the stress plateau as function of true stress and test temperature. This model permits to determine the Clausius-Clapeyron coefficient of the forward transformation.
\end{abstract}

\section{Introduction}

Superelastic behavior of near equiatomic Nickel-Titanium based shape memory alloys (NiTi SMA) is due to the complex interaction between several deformation mechanisms including lattice elasticity, phase transformations between austenite $(A)$, martensite $(M)$ and R-phase $(R)$, reorientations of $\mathrm{R}$ and/or $\mathrm{M}$ variants, twinning and detwinning phenomena and usual plasticity due to dislocations movements [1]. These phenomena are difficult to identify by considering only stress-strain curves of superelastic tensile tests. Using Dynamical Mechanical Analysis (DMA) to study shape memory alloys is a classical method to investigate phase transformation temperatures $[2,3,4,5,6,7]$, damping properties [8, 9, 10, 11, 12] or effect of fatigue [13]. Classically DMA tests are performed during a temperature sweep under a constant low stress; storage modulus and loss factor are measured as function of temperature. Consequently, phase transformation temperatures and damping properties are determined at low stress, what prevents from studying stress influence whereas this is of major importance.

In this paper, superelastic behavior of NiTi thin wires was investigated by using a nonconventional DMA which allows to measure the nominal storage modulus as function of nominal strain and stress during isothermal tensile tests at high level of stress. DMA tests were performed during cyclic superelastic tensile tests up to $10 \%$ of strain and monotonic tests up to failure at 
three temperatures above $A_{f}$ the reverse martensitic transformation finish temperature. The goal is to identify and study elasticity, phase transformations, localization and plasticity, by analyzing storage modulus evolution during isothermal superelastic tensile tests. A detailed analysis of the storage modulus evolution allows to estimate the elastic moduli of austenite and oriented martensite. From experimental results two models are proposed to simulate storage modulus evolution in cases where deformation is localized (during the stress plateau) or uniform (after the stress plateau), respectively. The last model and the results of the three isothermal tests are used to determine the Clausius-Clapeyron coefficient for the forward transformation.

\section{Materials and experimental set-up}

\subsection{Materials}

A commercial $\mathrm{NiTi}$ (Ti-50.9 at.\% Ni) wire provided by Fort Wayne Metals (reference : FWM\#1) with a diameter $\mathrm{d}=0.1 \mathrm{~mm}$ was used. This is a straight annealed NiTi wire for medical applications. Fig. 1a shows the nominal stress-strain curve of a tensile test performed at room temperature. Fig. $1 \mathrm{~b}$ shows the calorimetric curve obtained by Differential Scanning Calorimetry (DSC) with heating and cooling rates of $10^{\circ} \mathrm{C} \mathrm{min}{ }^{-1}$. A-R transformation was detected during cooling with a peak at $9.2^{\circ} \mathrm{C}$. During heating, reverse finish transformation temperature $A_{f}$ is determined equal to $26^{\circ} \mathrm{C}$.

\subsection{Experimental set-up and performed tests}

All tests were performed with a commercial DMA Netzsch-Gabo Eplexor 500N device. Unlike a classical DMA device, this non-conventional tensile test combines a standard tensile test with a DMA device. Fig. 2a describes schematically the device which is composed of:

1. a static unit on the upper side

2. a dynamic unit on the lower side

3. a thermal chamber

A static load is applied by means of the static unit. The static load can be driven in displacement, nominal strain, force, or nominal stress. A dynamic load is applied by the dynamic unit which is a shaker. The dynamic load can be driven in displacement, nominal strain, force, nominal stress. The thermal chamber permits to perform tests with a controlled temperature.

\subsubsection{DMA and Static Sweep (DMA-SS) test - Nominal storage modulus E'}

Fig. $2 b$ describes test named DMA and static sweep (DMA-SS). It consists in applying a sinusoidal displacement $\Delta L_{d y n}(t)$ of amplitude $\Delta L_{d y n}$ with a frequency $f$ superimposed on a static length $L_{\text {stat }}$. The length $L$ of the sample at any moment $t$ is given by:

$$
L=L_{\text {stat }}+\Delta L_{d y n}(t) \text { with } \Delta L_{d y n}(t)=\Delta L_{d y n} \sin (2 \pi f t)
$$


During this test, force $F$ is measured; this force is composed by a static part $F_{\text {stat }}$ and a sinusoidal dynamic part $F_{d y n}(t)$ of amplitude $F_{d y n}$ and is given by:

$$
F=F_{\text {stat }}+F_{d y n}(t) \text { with } F_{d y n}(t)=F_{d y n} \sin \left(2 \pi f\left(t-t_{\delta}\right)\right)
$$

$t_{\delta}$ being the phase difference between $\Delta L_{d y n}(t)$ and $F_{d y n}(t)$.

The nominal (or engineering) stress $\sigma$ and nominal dynamic stress amplitude $\sigma_{d y n}$ are determined by:

$$
\sigma=\frac{F_{s t a t}}{S_{0}} \text { and } \sigma_{d y n}=\frac{F_{d y n}}{S_{0}}
$$

with $S_{0}$ being the initial cross sectional area of the sample

The nominal (or engineering) strain $\varepsilon$ and nominal dynamic strain amplitude $\varepsilon_{d y n}$ are determined by:

with $L_{0}$ the initial length of the sample.

$$
\varepsilon=\frac{L_{s t a t}-L_{0}}{L_{0}} \text { and } \varepsilon_{d y n}=\frac{\Delta L_{d y n}}{L_{0}}
$$

For each dynamic cycle, the nominal storage modulus $E^{\prime}$ is given by the quotient between $\sigma_{d y n}$ the amplitude of the nominal dynamic stress and $\varepsilon_{d y n}$ the amplitude of the nominal dynamic strain :

$$
E^{\prime}=\frac{\sigma_{d y n}}{\varepsilon_{d y n}}
$$

\subsubsection{Performed tests}

A first reference DMA-SS test was performed at $T=60^{\circ} \mathrm{C}$ which is $34^{\circ} \mathrm{C}$ higher than $A_{f}$. Two other tests were performed at two other temperatures above $A_{f}$, i.e. at $T=80^{\circ} \mathrm{C}$ and $T=40^{\circ} \mathrm{C}$ respectively. The test at $60^{\circ} \mathrm{C}$ was used as the reference test because the test at $40^{\circ} \mathrm{C}$ can be influenced by the presence of R-phase (as shown by the DSC in Fig. 1.b). The test at $80^{\circ} \mathrm{C}$ implies higher stress and is more likely to be influenced by plasticity.

All samples were loaded up to $10 \%$ of nominal strain, unloaded then reloaded up to break. DMASS cycles were performed with $\varepsilon_{d y n}=0.1 \%$ and $f=100 \mathrm{~Hz}$. These parameters have been chosen to reduce the noise during the measure of $E^{\prime}$ and to allow measurements of $E^{\prime}$ at low static strain value of the order of $0.2 \%$ (the static strain value has to be greater than the dynamic strain amplitude).

\subsection{Definition of true storage modulus $E_{t}^{\prime}$}


The nominal storage modulus $E^{\prime}$ is, as shown in Eq. 5, calculated from the nominal stress and strain defined in Eq. 3 and Eq. 4 respectively. The true storage modulus $E_{t}^{\prime}$ is calculated from the true strain $\varepsilon_{t}=\ln \left(\frac{L}{L_{0}}\right)$ and from the true stress $\sigma_{t}=\frac{F}{S}$ with $S$ the current cross section area. The true strain is given by:

$$
\varepsilon_{t}=\ln \left(\frac{L}{L_{0}}\right)=\ln (1+\varepsilon)
$$

By noting $v$ the Poisson's ratio, the current cross section area is :

$$
S=S_{0} \exp \left(-2 v \varepsilon_{t}\right)=(1+\varepsilon)^{-2 v}
$$

The true stress $\sigma_{t}$ is deduced from the nominal stress $\sigma$ and strain $\varepsilon$ by:

$$
\sigma_{t}=\frac{F}{S}=\sigma \exp \left(2 v \varepsilon_{t}\right)=\sigma(1+\varepsilon)^{2 v}
$$

The true storage modulus $E_{t}^{\prime}$ is then given by:

$$
E_{t}^{\prime}=\frac{d \sigma_{t}}{d \varepsilon_{t}}=E^{\prime}(1+\varepsilon)^{(1+2 v)}+2 v \sigma(1+\varepsilon)^{2 v}
$$

Perfect plastic or transformation deformation mechanisms occur without volume change. By assuming isotropy and incompressibility, the Poisson's ratio $v$ is equal to 0.5 . Then the true stress and true storage modulus are given by:

$$
\sigma_{t}=\sigma(1+\varepsilon) \quad \text { and } \quad E_{t}^{\prime}=E^{\prime}(1+\varepsilon)^{2}+\sigma(1+\varepsilon)
$$

In the following, when not specified, the true stress and true storage modulus are calculated Eq. 10, assuming no volume change.

In order to illustrate the differences between nominal and true values, Figure 3 shows the stress-strain curves (Fig. 3a) and the storage modulus-strain curves (Fig. 3b) during a DMA-SS test performed on a soft annealed $\mathrm{Cu}$ wire of diameter $0.5 \mathrm{~mm}$. The DMA-SS parameters $\left(\varepsilon_{d y n}=0.1 \%\right.$ and $f=100 \mathrm{~Hz}$ ) were identical to those used for the studied NiTi wire. The nominal values are plotted in red, the true values with $v=0.5$ using Eq.10 are plotted in black. The difference between nominal and true stresses (Fig. 3a) is well-known, especially in plasticity. The difference between nominal and true storage moduli (Fig. 3b) is less known. In the majority of publications this difference is not clarified because conventional DMA are performed during a temperature sweep under small stress and strain $[2,3,4,5,6,7]$. The results shown in Fig. 3b illustrate that for a nominal strain greater than $2 \%$, the difference between nominal and true storage moduli is significant. For a strain equal to $10 \%$, the true storage modulus $E_{t}^{\prime}$ is $25 \%$ higher than $E^{\prime}$ the 
nominal storage modulus. The true value of the storage modulus using Eq. 9 and $v=0.33$ is plotted in blue; the true modulus is still more than $20 \%$ higher than $E^{\prime}$ the nominal storage modulus.

A second conclusion of the DMA-SS test performed on the $\mathrm{Cu}$ wire concerns the determination of the elastic modulus for an elastoplastic material. A first method consists in measuring the slope of the stress-strain curve in the elastic zone, i.e. for low values of strain and stress; in that case, it is not necessary to distinguish nominal and true values of strain and stress because the differences are very weak. The DMA-SS test performed in our study provides a second method. In fact, this method consists in performing small elastic unloadings during the tensile loading in the plastic zone; the storage moduli are the slopes of the stress-strain unloading curves. As shown in Fig. 3b, the nominal storage modulus $E^{\prime}$ decreases with increasing strain. On the contrary, the true storage modulus $E_{t}^{\prime}$ is almost independent of the plastic strain. Thus the estimation of the elastic modulus from the nominal storage modulus during a DMA-SS test would imply that the elastic modulus would depend on the plastic strain, which is not relevant. On the contrary, the estimation of the elastic modulus from the true storage modulus during the DMASS test on a elastoplastic material is not dependent on the plastic strain. This result is consistent with the definition of elastic modulus used in theoretical elastoplasticity [14].

Thus, during a DMA-SS test, the elastic modulus has to be evaluated from the determination of the true storage modulus variation $E_{t}^{\prime}$ and not from that of the nominal storage modulus $E^{\prime}$; this conclusion is important for large static strain, typically higher than $2 \%$.

\section{Experimental Results}

Fig. 4, Fig. 5 and Fig. 6 show DMA-SS results at $60^{\circ} \mathrm{C}, 80^{\circ} \mathrm{C}$ and $40^{\circ} \mathrm{C}$, successively. The measure of loss factor is too noisy and will not be used. Upper and lower curves of subfigures a) show nominal stress $\sigma$-nominal strain $\varepsilon$ and nominal storage modulus $E^{\prime}$-nominal strain $\varepsilon$ curves, respectively for the specimen loaded up to $10 \%$ of strain and then unloaded. Subfigures b) show storage modulus $E^{\prime}$ as function of nominal stress $\sigma$ during this cycle. Singular points have been numbered, (0) to (4) during loading and (5) to (8) during unloading.

Similar curves are plotted using solid lines for the reloading up to break in the subfigures c) and d). Singular points (5') and (6') are associated to this test up to break.

\subsection{Test at $60^{\circ} \mathrm{C}$}

Cyclic stress $\sigma$-strain $\varepsilon$ curve (Fig. 4a) exhibits a classical superelastic behaviour. Loading and unloading plateaus occur for nominal stresses of $770 \mathrm{MPa}$ and $530 \mathrm{MPa}$, respectively. During loading, $E^{\prime}$ decreases monotonically between (0) and (1) with an initial value of $70 \mathrm{GPa}$. At point (1), matching with the start of the loading stress plateau, $E^{\prime}$ reaches $52 \mathrm{GPa}$. Plateau nominal stress is globally constant, after a little drop at point (2). Between (1) and (3), $E^{\prime}$ continues to 
decrease almost linearly to reach $35 \mathrm{GPa}$ in (3). At the end of the plateau in (3), $E^{\prime}$ starts to increase monotonically to reach $47 \mathrm{GPa}$ in (4).

During unloading, the reverse evolution is observed. $E^{\prime}$ decreases between (4) and (5). The unloading plateau starts in (5) with a stress jump between (5) and (6), associated with a step increase of $E^{\prime}$. During the stress plateau between (6) and (7), $E^{\prime}$ increases almost linearly up to 56 $\mathrm{GPa}$ at point (7) that corresponds to the end of the plateau. During the last stage of the unloading between (7) and (8), $E^{\prime}$ continues to increase to reach $70 \mathrm{GPa}$ at the end of unloading in (8).

Figure $4 \mathrm{~b}$ shows the evolution of $E^{\prime}$ as function of stress during the previous cyclic test. During loading, $E^{\prime}$ decreases monotonically before the stress plateau until point (1). $E^{\prime}$ is almost constant during the stress drop between (1) and (2). Then $E^{\prime}$ decreases sharply during the stress plateau between (2) and (3). After the stress plateau, $E^{\prime}$ increases between points (3) and (4). Reverse evolution is observed during unloading. Initial and final values of $E^{\prime}$ at zero stress in (0) and (8) respectively, are identical and equal to $70 \mathrm{GPa}$ as shown in Fig. 4b.

The test up to break (Fig. 4c and Fig. 4d), shows the same evolution than during the loading of the cyclic test. After the stress plateau, $E^{\prime}$ increases; the increase is slowing down with strain increasing. $E^{\prime}$ reaches $53 \mathrm{GPa}$ at point (6').

\subsection{Test at $80^{\circ} \mathrm{C}$}

Figure 5 shows results for the test at $\mathrm{T}=80^{\circ} \mathrm{C}$. Stress-strain curve (Fig. $5 \mathrm{a}$ ) exhibits a classical superelastic behavior like at $\mathrm{T}=60^{\circ} \mathrm{C}$. Loading and unloading stress plateaus occur for stresses of $900 \mathrm{MPa}$ and $670 \mathrm{MPa}$ respectively.

Storage modulus-strain curve follows similar evolution than at $\mathrm{T}=60^{\circ} \mathrm{C}$. Initial and final values of $E^{\prime}$ at zero stress are identical (Fig. 5b) and equal to $70 \mathrm{GPa}$ which is identical to the value measured at $60^{\circ} \mathrm{C}$. The storage modulus variations on one hand between (0) and (1) and on the other hand between (7) and (8) are both smaller than the same variations measured at $60^{\circ} \mathrm{C}$.

The test up to break (Fig. $5 \mathrm{c}$ and Fig. $5 \mathrm{~d}$ ), shows the same evolution as at $60^{\circ} \mathrm{C}$, and $E^{\prime}$ increases up to point (6') to reach $50 \mathrm{GPa}$.

\subsection{Test at $40^{\circ} \mathrm{C}$}

Figure 6 shows results for $\mathrm{T}=40^{\circ} \mathrm{C}$. Similarly to the tests performed at $60^{\circ} \mathrm{C}$ and $80^{\circ} \mathrm{C}$, the stress-strain curve (Fig. 6a) exhibits a classical superelastic behavior. Loading stress plateau occurs for a stress of $636 \mathrm{MPa}$ and unloading plateau for a stress of $376 \mathrm{MPa}$. 
Storage modulus-strain curve follows same evolution as $T=60^{\circ} \mathrm{C}$ and $T=80^{\circ} \mathrm{C}$. Initial and final values of $E^{\prime}$ at zero stress are identical (Fig. 6b), equal to $66 \mathrm{GPa}$, which is smaller than the value measured at $60^{\circ} \mathrm{C}$ and $80^{\circ} \mathrm{C}$. The storage modulus variations on one hand between (0) and (1) and on the other hand between (7) and (8) are both larger than the same variations measured at $60^{\circ} \mathrm{C}$ and $80^{\circ} \mathrm{C}$.

The test up to break (Fig. $5 \mathrm{C}$ and Fig. $5 \mathrm{~d}$ ), shows the same evolution at $60^{\circ} \mathrm{C}$ and $80^{\circ} \mathrm{C}$, and $E^{\prime}$ increases up to point (6') to reach $55 \mathrm{GPa}$.

\section{Analysis of DMA results}

\subsection{Analysis of $E^{\prime}$ evolution during loading}

The stage before the stress plateau (i.e. between (0) and (1)) is usually considered to be associated with the elastic deformation austenite [17]. Several authors [15, 16] have shown that strain is uniform along the wire during this stage. As shown in Figures 4, 5, 6, the storage modulus $E^{\prime}$ decreases monotonically between (0) and (1). The monotonic decrease of $E^{\prime}$ between (0) and (1) during a DMA and Static Sweep (DMA-SS) test on a NiTi wire proves that deformation mechanisms other than elasticity and plasticity are involved during this stage. It can be assumed that these additional deformation mechanisms are due to stress induced phase transformations, either A-R and/or A-M transformations [18], even at low stress. At point (0) the wire is mainly in austenite with some amount of martensite and Rphase. The storage modulus is estimated by $E^{\prime}=$ $\frac{\sigma_{d y n}}{\varepsilon_{d y n}}$. In this stage, the total dynamic strain $\varepsilon_{d y n}$ can be expressed as the sum of a lattice elastic dynamic strain $\left(\varepsilon_{d y n}\right)_{e l}$ and of a phase transformation dynamic strain $\left(\varepsilon_{d y n}\right)_{\text {transf }}$. Introducing the elastic modulus $E=\frac{\sigma_{d y n}}{\left(\varepsilon_{d y n}\right)_{e l}}$, the storage modulus is expressed as $E^{\prime}=E \frac{\left(\varepsilon_{d y n}\right)_{e l}}{\varepsilon_{d y n}}=$ $E\left(1-\frac{\left(\varepsilon_{d y n}\right)_{\text {transf }}}{\varepsilon_{d y n}}\right)$. The monotonic decrease of the storage modulus $E^{\prime}$ with increasing static strain (or static stress) during stage (0) and (1) is thus only due to the increase of transformation mechanisms.

During the stress plateau, between (2) and (3), the nominal stress is almost constant and the nominal storage modulus $E^{\prime}$ decreases almost linearly with increasing strain. It was shown that deformation is localized along the wire in this stage $[15,16]$. The number of regions and the number of fronts are increasing with increasing strain rate, as shown by $\mathrm{Ng}$ and Sun [19]. For low strain rate, the wire is divided into two regions (a) and (b), separated by a localization front as illustrated in Fig. 8. The fraction of martensite and the strain in region (a) are very high whereas they are very low in region (b). The front of localization moves from left to right with increasing wire strain. At point (3) localization is completed, the sample is fully in state (a) and uniform deformation replaces localized deformation. The quasi-linear evolution of the storage modulus with strain during the stress plateau can be explained by this deformation localization 
phenomenon and by a storage modulus difference between regions (a) and (b). A model will be proposed in subsection 6.1.

After the stress plateau, the deformation is usually associated with the elasticity of oriented martensite [17]. The wire deformation is uniform, as shown in [15, 16]. Similarly to the stage between (0) and (1), the continuous increase of $E^{\prime}$ during the stage between (3) and (4) shows that deformation is not only elastic and that phase transformations and/or variants reorientation occur.

The evolution up to rupture between (4) and ( $\left.5^{\prime}\right)$ is presented in figures $4 \mathrm{c}$ and $4 \mathrm{~d}$ at $60^{\circ} \mathrm{C}$. $E^{\prime}$ tends to be constant with increasing strain. This is explained by the decrease of the transformation and reorientation deformation mechanisms with increasing strain, being replaced by plasticity mechanisms between (5') and (6').

\subsection{Analysis of $E^{\prime}$ evolution during unloading}

The stage between (4) and (5) is usually associated with the elastic deformation of oriented martensite [17]. It was shown that the wire deformation is uniform during this stage [15, 16]. $E^{\prime}$ continuous decrease shows that this stage is not only elastic and that reverse transformation occurs.

The stage during the lower stress plateau, between (6) and (7), is similar to the stage during the upper stress plateau, between (2) and (3), during loading. Nominal stress is nearly constant and $E^{\prime}$ increases almost linearly with decreasing strain. Similarly than during the upper plateau, the $E^{\prime}$ evolution between (6) and (7) is due to the localization phenomenon and to the existence of regions with different states along the wire.

The stage between (7) and (8) corresponds to the stage between (0) and (1) during the loading and a similar analysis can be done. The increase of $E^{\prime}$ with decreasing strain shows that this stage is not purely elastic (Fig. 8), and that a reverse transformation occurs during this stage. Values at point (8) are the same as for the initial stage, i.e $70 \mathrm{GPa}$ for $60^{\circ} \mathrm{C}$ and $80^{\circ} \mathrm{C}$, and $65 \mathrm{GPa}$ for $40^{\circ} \mathrm{C}$ (close to $A_{f}$ ).

\subsection{Identification of deformation phenomena present in NiTi wire from stress and storage modulus $E^{\prime}$ evolutions}

In conclusion, analyzing both stress $\sigma(\varepsilon)$ and $E^{\prime}(\varepsilon)$ curves during a tensile test allows identifying the majority of the phenomena. $E^{\prime}$ evolution measurement brings new information and clarifies the ambiguities we may have by analyzing only stress as function of strain. Table 1 shows the evolution of $\sigma(\varepsilon)$ and $E^{\prime}(\varepsilon)$ to identify elasticity, transformation and or reorientation, localization and plasticity during loading. To simplify interpretation, arrows are used to code evolution. $\rightarrow, \pi, \searrow$ mean that the value is constant, increases and decreases with increasing strain successively. 
For the NiTi wire studied, there is no stage with constant value of the storage modulus; it means that there is no deformation stage for which the deformation is purely elastic or purely plastic, even for tests performed in the temperature range of superelastic behavior. Phase transformations and/or variant reorientations occur at the beginning and the ending of the loading, separated by a deformation stage characterized by a deformation localization phenomenon.

\section{How to determine elastic moduli of austenite and oriented martensite from DMA tests?}

\subsection{Measurement methods}

For a usual elastoplastic alloy such as the soft annealed Cu wire shown in Figure 3, a first method to determine the elastic modulus is based on the measurement of the slope of a tensile stress-strain curve. For an elastoplastic alloy, the elastic modulus is the initial slope. This first method is called "the slope method". A second method is to deduce this elastic modulus from the measurement of the storage modulus evolution during a DMA-SS test. It was shown in Fig. 3 that the elastic modulus for an elastoplastic alloy is equal to the true storage modulus independently of the strain/stress. This second method is called "the storage modulus method".

The behavior of a NiTi SMA is much more complicated than a usual elastoplastic alloy; it is due to complex interaction between several deformation mechanisms, including lattice elasticity, phases transformations and plasticity. In order to determine elastic moduli of austenite and oriented martensite, table 2 shows the values deduced from the slopes of the stress-strain curves during the tensile tests at $40^{\circ} \mathrm{C}, 60^{\circ} \mathrm{C}$ and $80^{\circ} \mathrm{C}$. Table 3 presents measurements deduced from the storage moduli evolution during these same tests.

Table 2 presents values of slopes of the tensile stress-strain curves at different stages of the cyclic stress-strain curves plotted in Fig. 4.a, 5.a and 6.a. All the slopes are calculated with a stress range $\Delta \sigma=200 \mathrm{MPa}$. They are calculated from the nominal stress-strain curves $(\Delta \sigma / \Delta \varepsilon)$ or from the true stress-strain curves $\left(\Delta \sigma_{t} / \Delta \varepsilon_{t}\right)$. The second column shows the slopes calculated in point (0). $\Delta \sigma / \Delta \varepsilon$ and $\Delta \sigma_{t} / \Delta \varepsilon_{t}$ are identical in this deformation range. The third and fourth columns are the slopes calculated during loading after the stress plateau in (3). The fifth and sixth columns are the slopes calculated at the start of unloading in (4).

Table 3 presents values deduced from the DMA-SS tests. The second column shows the values of the initial nominal storage modulus $E^{\prime}$ at point (0); $E^{\prime}$ is identical to the true storage modulus $E^{\prime}$ in this deformation range. The third and fourth columns show the values of $E^{\prime}$ and $E^{\prime}{ }_{t}$ in (4), respectively; as shown in Fig.4.b, 5.b, and 6.b, the values of the storage moduli in (4) at the end of the loadings are equal to those at the start of the unloadings. The fifth and sixth columns show the values of $E^{\prime}$ and $E^{\prime}{ }_{t}$ at the rupture point in $\left(6^{\prime}\right)$ of Fig. 4.d, 5.d and 6.d. 


\subsection{Elastic modulus of austenite $E_{A}$}

The first method to determine elastic modulus of austenite $E_{A}$ consists in using the "slope method", which is the most popular method [17]. From the second column of table 2, $E_{A}$ is determined equal to $69 \mathrm{GPa}$ at $60^{\circ} \mathrm{C}$ and $80^{\circ} \mathrm{C}$ and a little smaller $63 \mathrm{GPa}$ at $40^{\circ} \mathrm{C}$. The DMA-SS tests performed in this paper allow using the "storage modulus method". By using the second column of table $3, E_{A}$ it is determined equal to $66 \mathrm{GPa}$ at $40^{\circ} \mathrm{C}$ and $70 \mathrm{GPa}$ at higher temperatures. The values determined using the two methods are very close for the three test temperatures. The lower values at $40^{\circ} \mathrm{C}$ can be easily explained by the residual Rphase transformation which occurs between (0) and (1).

In conclusion, the elastic modulus of austenite $E_{A}$ is estimated equal to $70 \mathrm{GPa}$ using both "slope method" and "storage modulus method".

\subsection{Elastic modulus of oriented martensite $E_{M}$}

Macroscopic elastic modulus of oriented martensite $E_{M}$ is usually estimated from the slope of the nominal stress-strain curve after the stress plateau $[17,20]$. The slopes are taken either during loading after the stress plateau, which are the values in the column (3) of the table 2 , or at the start of the unloading after the stress plateau which are the values in the column (5). The values of the slopes during loading in column (3) are very low, of the order of $17 \mathrm{GPa}$, and almost independent of the temperature. Using column (5) gives higher values ranging from $38 \mathrm{GPa}$ at $40^{\circ} \mathrm{C}$ to $30 \mathrm{GPa}$ at $80^{\circ} \mathrm{C}$. All the values in columns (3) and (5) are low compared to the elastic modulus of austenite. The low values of columns (3) are explained by the fact that the transformation is not completed after stress plateau as explained in paragraph 4.3. The low values of columns (5) mean that reverse transformation mechanisms occur upon unloading; the decrease of the slope with increasing temperature is likely due to the increase of reverse transformation and/or reverse detwinning due to higher back stress, prior to the unloading stress plateau.

The slopes can be estimated from the true stress-strain curves rather than from the nominal stress-strain curves. The values in column (4) are increased compared to those of the column (3). Similarly, the values in column (6) are also increased compared to the column (5), ranging from $41 \mathrm{GPa}$ at $40^{\circ} \mathrm{C}$ to $34 \mathrm{GPa}$ at $80^{\circ} \mathrm{C}$. The difference between values obtained from nominal or true stress-strain curves is easily explained by the fact that the reduction of current specimen section and the increase of current specimen length is taken into account when using true stress-strain curves. This precaution is scarcely taken.

Using either nominal or true stress-strain curves, the highest value of the estimation of martensite modulus is $41 \mathrm{GPa}$. As pointed out in [29], the best measurement of martensite modulus which can be reached from stress-strain curve is obtained during unloading of stressinduced martensite. This value is of the same order that the elastic modulus proposed by the provider for wire in martensitic state [28]. However, it is still low compared to the elastic modulus of austenite. 
The "storage modulus method" is an alternative way to estimate elastic modulus of oriented martensite. As shown in column (3) of table 3, at point (4) the nominal storage modulus decreases from $50 \mathrm{GPa}$ at $40^{\circ} \mathrm{C}$ to $42 \mathrm{GPa}$ at $80^{\circ} \mathrm{C}$. These values are higher than the values determined by the slope method at the same point ( $38 \mathrm{GPa}$ at $40^{\circ} \mathrm{C}$ to $30 \mathrm{GPa}$ at $80^{\circ} \mathrm{C}$ ), as summarized in columns (5) of table 2 . Indeed, the "storage modulus method" is based on the measurement of $E^{\prime}=\frac{\sigma_{d y n}}{\varepsilon_{d y n}}$ as shown in eq (5). $E^{\prime}$ is measured with a dynamic strain of $0.1 \%$ which corresponds approximately to a dynamic stress $\sigma_{d y n}$ of the order of $50 \mathrm{GPa}$. The slope method uses a stress range $\Delta \sigma=200 \mathrm{MPa}$. As $\sigma_{d y n}$ is lower than $\Delta \sigma$, the moduli estimated at point (4) by the "storage modulus method" are higher than by the "slope method" due to activation of less inelastic deformation mechanisms by the first method. An other way to decrease the inelastic deformation mechanisms is to increase the strain till the rupture of the specimen. At the rupture, the nominal storage modulus is equal to $55 \mathrm{GPa}$ at $40^{\circ} \mathrm{C}$ and of $50 \mathrm{GPa}$ at $80^{\circ} \mathrm{C}$. These values are higher than the values at point (4) to the activation of less inelastic deformation mechanisms.

The values deduced from the determination of the true storage modulus using Eq. 10 are given in columns (4) and (6) of table 3 for the point (4) and (6') of fig.4,5 and 6 respectively. Comparison of columns ( 3 ) and (4) for the point (4) and columns (5) and (6) for the point ( $6^{\prime}$ ) show that the differences between the nominal and the true storage moduli is important at this strain level. This effect was not taken into account in [24] and leads to an underestimated value for the macroscopic elastic modulus of oriented martensite $E_{M}$.

In figure 9, the true storage modulus using Eq. 10 is plotted in full lines for stress higher than the plateau stresses as function of the true stress for the three tested temperatures, for the tests at rupture shown in Fig. 4.c, 5.c and 6.c. The best estimation for the macroscopic modulus of martensite is the asymptotic value of these three curves, which is equal to $73 \mathrm{GPa}$. Using Eq. 9 and a Poisson's ratio $v=0.33$, the asymptotic value is equal to $70 \mathrm{GPa}$.

In conclusion, the elastic modulus of martensite can not be deduced from nominal or true stress-strain curves. It can be estimated using "storage modulus method" by considering the true storage modulus and not the nominal storage modulus. With this method, the macroscopic elastic modulus $E_{M}$ of oriented martensite of the studied wire is estimated equal to $73 \mathrm{GPa}$.

\subsection{Comparison with values of literature}

Many articles proposed experimental values of elastic moduli of austenite and martensite $[20,21,22,23,24]$. In this paper, the elastic moduli have been determined at room temperature for a thin Ti-50.9 at.\% Ni wire in austenitic state under stress-free condition. The elastic moduli of austenite and of stress-induced martensite were measured during a tensile test, at low and high stress respectively. The stress-strain deformation response include contributions from elastic, transformation, twinning and plastic deformation; this lead to a strong coupling between activity of deformation mechanisms such as stress induced B2=> B19'=>B2T martensitic 
transformation into twinned austenite coupled with dislocation slip [25bis]. The main difficulty of the measure is to separate the elastic deformation mechanisms from all the other deformation mechanisms occurring during the deformation of the wire. In our experiments, the Dynamic Mechanical Analysis has been used.

The process of fabrication induces different textures, and elastic moduli are different between a rod [21, 20, 22, 23] and a thin wire [20,24]. Moreover, elastic moduli, especially for stress induced martensite, can be strongly anisotropic [24, 25]. As pointed out by Bucsek et al [29], "the Young's modulus of polycrystalline NiTi alloys is not a fixed number and changes with both processing and in operando deformations".

The obtained values in the present study are compared to the values obtained by Young et al. [20] which determined the elastic moduli of austenite and stress induced martensite during a tensile test of a similar wire. These last authors measured microscopic elastic moduli with in situ X-ray diffraction extensometry. For the austenite B2, Young et al determine Young's moduli for (100),(110),(200) and (211) direction ranging between $51 \mathrm{GPa}$ and $72 \mathrm{GPa}$, with an average value of $57 \mathrm{GPa}$. For the martensite B19' (001), they obtained a value of $69 \mathrm{GPa}$. The results obtained in the present work using Dynamic Mechanical Analysis are within range of values reported by Young et al. and confirm that for the studied wire the elastic modulus of oriented martensite is of the same order than of austenite and even a little higher.

\section{From the modelling of DMA results to determination of Clausius- Clapeyron coefficients}

Experimental results concerning the storage modulus measurement during superelastic tensile tests have been presented in section 4 . In section 5 , the true storage moduli evolutions $E^{\prime}{ }_{t}$ with strain have been used to determine the austenite elastic modulus $E_{A}$ as the initial value of $E^{\prime}{ }_{t}$ at low strain-stress and the elastic modulus of oriented martensite, $E_{M}$, as the asymptotic value of $E_{t}^{\prime}$ during the test at rupture for high values of strain/stress.

This section is devoted to further analyze the evolution of storage modulus during all the tensile tests by proposing a first model to simulate the evolution of the nominal storage modulus during the stress plateau and a second model to simulate the evolution of the true storage modulus after the plateau. This second model permits to determine the Clausius-Clapeyron coefficient of the forward transformation.

During loading, three zones are identified in Fig. 4c and 4d. Zones (I) and (III) correspond to uniform wire deformation stages, associated to the start and end of $A / R-M$ uniform transformation, respectively. Zone (II) corresponds to the stress plateau during which the deformation is localized. In the following subsections, models are proposed to simulate the evolution of storage moduli for zones (II) and (III). The model proposed in the subsection 6.1 takes into account the deformation localization during the stress plateau. This model is based on mixture law ; and simulates the evolution of the nominal storage modulus $E^{\prime}$ as function of the nominal strain during a tensile test. 
The model proposed in the subsections 6.2 and 6.3 takes into account that the deformation is uniform during the stage after the stress plateau, and that the true nominal storage modulus $E_{t}^{\prime}$ is function of temperature and true stress. In subsection 6.2 , the dependence of $E_{t}^{\prime}$ on true stress is modeled at $60^{\circ} \mathrm{C}$. In subsection 6.3 , it is shown that the dependence of $E_{t}^{\prime}$ on true stress at $40^{\circ} \mathrm{C}$ and $80^{\circ} \mathrm{C}$ can be deduced from the model established at $60^{\circ} \mathrm{C}$ by a ClausiusClapeyron like relation; this allows to estimate the Clausius-Clapeyron coefficient of the forward transformation without using the plateau stress, which is now well-known not to be the onset of the transformation but that of the localization phenomenon [18].

\subsection{Modelling of nominal storage modulus $E^{\prime}$ evolution during the stress plateau}

Figure 8 shows a scheme of the deformation of the tested wire in the zone II. At point (0), the initial sample length is $L_{0}$. The deformation is uniform between point (0) and (2).

During the stress plateau between (2) and (3), for a given static nominal strain $\varepsilon$, the specimen length is $L_{0}(1+\varepsilon)$. The specimen is constituted of two regions (a) and (b) separated by a localization front. The lengths of regions are $L_{a}(\varepsilon)$ and $L_{b}(\varepsilon)$ respectively.

The nominal strains are constant and uniform in the regions (a) and (b), as shown in [16, $18,26]$; they are noted $\varepsilon_{a}$ for the higher deformed region (a) and $\varepsilon_{b}$ for the region (b) which is mostly in austenitic phase. The nominal nominal stress $\sigma_{a}$ in region (a) is equal to $\sigma_{b}$ the nominal stress in region (b) and equal to the nominal stress $\sigma$ applied to the wire.

Delobelle et al. [16] observed that for a small unloading that occurs when the deformation is localized, the front of localization does not move. This observation leads to assume that during a storage modulus measurement the localization front does not move, since the DMA consists of small cycles of loading/unloading. Thus during DMA tests around a static strain $\varepsilon, L_{a}(\varepsilon)$ and $L_{b}(\varepsilon)$ are constant. During a DMA measurement, all regions are under the same dynamic stress $\sigma_{d y n}$ and the length variation $\Delta L_{d y n}$ is the sum of $\Delta L_{d y n(a)}$ and $\Delta L_{d y n(b)}$ of regions (a) and (b). Thus:

$$
\Delta L_{d y n}=\sigma \frac{\sigma_{d y n}}{E^{\prime}} L_{0}=\Delta L_{d y n(a)}+\Delta L_{d y n(b)}
$$

with : $\Delta L_{d y n(a)}=\frac{\sigma_{d y n}}{E^{\prime}{ }_{a}} L_{a 0}$ and $\Delta L_{d y n(b)}=\frac{\sigma_{d y n}}{{E^{\prime}}_{b}} L_{b 0}, L_{a 0}$ and $L_{b 0}$ being the undeformed lengths of regions (a) and (b) given by :

$$
L_{a 0}=\frac{L_{a}(\varepsilon)}{1+\varepsilon_{a}} ; L_{b 0}=\frac{L_{b}(\varepsilon)}{1+\varepsilon_{b}}
$$

By assuming that nominal storage modulus $E_{a}^{\prime}$ and $E_{b}^{\prime}$ are uniform in region (a) and (b), the equation (11) leads to the following equation:

$$
\frac{L_{0}}{E^{\prime}}=\frac{L_{a 0}}{E_{a}^{\prime}}+\frac{L_{b 0}}{E_{b}^{\prime}}
$$


The initial and current lengths of the wire are respectively :

$$
L_{0}=L_{a 0}+L_{b 0} \quad \text { and } \quad L_{0}(1+\varepsilon)=L_{a}(\varepsilon)+L_{b}(\varepsilon)
$$

The combination of equations 12,13 and 14 gives :

$$
E^{\prime}(\varepsilon)=\frac{E_{a}^{\prime} E_{b}^{\prime}\left(\varepsilon_{a}-\varepsilon_{b}\right)}{E_{b}^{\prime}\left(\varepsilon-\varepsilon_{b}\right)+E_{a}^{\prime}\left(\varepsilon_{a}-\varepsilon\right)}
$$

which permits to express the evolution of $E^{\prime}$ as function of the given nominal strain $\varepsilon$ of the nominal storage moduli $E_{a}^{\prime}$ and $E_{b}^{\prime}$ and of the nominal strains $\varepsilon_{a}$ and $\varepsilon_{b}$ of regions (a) and (b).

For a test performed at low strain rate, nominal plateau stress is constant, $\sigma_{2}=\sigma_{3}$ so that : $E_{a}^{\prime}=E_{3}^{\prime} ; E_{b}^{\prime}=E_{2}^{\prime} ; \varepsilon_{a}=\varepsilon_{3} ; \varepsilon_{b}=\varepsilon_{2}$ and :

$$
E^{\prime}(\varepsilon)=\frac{E_{3}^{\prime} E_{2}^{\prime}\left(\varepsilon_{3}-\varepsilon_{2}\right)}{E_{2}^{\prime}\left(\varepsilon-\varepsilon_{2}\right)+E_{3}^{\prime}\left(\varepsilon_{3}-\varepsilon\right)}
$$

These $E^{\prime}$ evolutions for zone (II) as predicted by Eq. 16 are plotted in dashed lines in Fig. 4c, Fig. 5c, Fig. 6 c and fit well with the experimental curves.

\subsection{Modelling of $E_{t}^{\prime}$ evolution during uniform deformation stage (III) at $T=60^{\circ} \mathrm{C}$}

The experimental evolution of the true storage modulus $E_{t}^{\prime}$ during uniform deformation stage (III) at $\mathrm{T}=60^{\circ} \mathrm{C}$ is plotted in full lines in Fig. 9. During this stage, deformation mechanisms include elasticity, plasticity and martensitic transformation. When the deformation of an alloy is only due to the two first mechanisms, $E_{t}^{\prime}$ is constant as shown in Fig. 3 for a soft annealed $\mathrm{Cu}$ wire. Fig. 9 shows that for the studied NiTi wire, $E_{t}^{\prime}$ increases after the stress plateau to reach asymptotically the elastic modulus $E_{M}$ of the oriented martensite. This increase is due to the decreasing transformation mechanism with increasing strain and stress.

At the point (3), the beginning of zone (III), the true stress and true storage modulus at $60^{\circ} \mathrm{C}$ are $\sigma_{t 3}$ and $E_{t 3}^{\prime}$ respectively. It is proposed to fit the evolution of $E_{t}^{\prime}$ with the true stress $\sigma_{t}$ in the zone (III) at $60^{\circ} \mathrm{C}$ by a hyperbolic tangent function

$$
E_{t}^{\prime}\left(\sigma_{t}, T_{0}=60^{\circ} C\right)=E_{t 3}^{\prime}+\left(E_{M}-E_{t 3}^{\prime}\right) \tanh \left[K_{3} \frac{\sigma_{t}-\sigma_{t 3}}{E_{M}-E_{t 3}^{\prime}}\right]
$$

$K_{3}$ is a fitting parameter and represents the slope of the curve $E_{t}^{\prime}$-true stress at point (3) in Fig. 9.

The equation 17 fitted with $K_{3}=41$ is plotted in dashed lines in Fig. 9 and fits very well with experimental true storage modulus evolution at $60^{\circ} \mathrm{C}$.

\subsection{Determination of Clausius Clapeyron coefficient for $A-M$ transformation}


Martensitic transformations are first order transformations which can be stress induced. During a test performed at a reference temperature $T_{0}$, the transformation stress is noted $\sigma_{S I M}\left(T_{0}\right)$. The transformation stress $\sigma_{S I M}(T)$ at any other test temperature Tabove $A_{\mathrm{f}}$ is deduced from $\sigma_{S I M}\left(T_{0}\right)$ by using the Clausius-Clapeyron relation [27] which writes :

$$
\sigma_{S I M}(T)=\sigma_{S I M}\left(T_{0}\right)+C_{A M}\left(T-T_{0}\right)
$$

The Clausius-Clapeyron relation expresses that there is a linear relation between the transformation stress and the test temperature, $C_{A M}$ being the Clausius-Clapeyron coefficient for the A-M transformation.

For tensile tests of NiTi shape memory alloys, $\sigma_{S I M}$ is estimated with the value of the plateau stress in stress-strain curves, assuming that transformation starts only for stress equal to the plateau stress. In our experiments, values of forward plateau stresses were calculated for a strain of $4 \%$. A linear fitting allowed to determine $C_{A M}=6.6 \pm 0.5 \mathrm{MPa} \mathrm{K}^{-1}$. However, it is now well known that the stress plateaus are due to the localization phenomena and not only to the transformation [26]. Thus estimating the transformation stress as the plateau stress can lead to inaccurate measures of $C_{A M}$.

Another method to evaluate $C_{A M}$ is proposed in this paper. It is based on the dependence on temperature $T$ of the evolution of $E_{t}^{\prime}$ with the true stress $\sigma_{t}$. Eq. (17) proposes an equation $E_{t}^{\prime}\left(\sigma_{t}, T_{0}\right)$ to model this evolution for the test at $T_{0}=60^{\circ} \mathrm{C}$. The Clausius-Clapeyron relation shown in Eq. (18) allows to extend this model to other test temperatures $T$ by :

$$
E_{t}^{\prime}\left(\sigma_{t}, T\right)=E_{t}^{\prime}\left(\sigma_{t}-C_{A M}\left(T-T_{0}\right), T_{0}\right)
$$

This relation expresses that the intensity of the transformation at the temperature $T$ and for the true stress $\sigma_{t}$ is identical to that at the temperature $T_{0}$ and for the true stress $\sigma_{t}-C_{A M}\left(T-T_{0}\right)$.

The $C_{A M}$ Clausius Clapeyron coefficient in Eq. 19 was chosen to minimize the gap between model and experimental curves both at $40{ }^{\circ} \mathrm{C}$ and $80^{\circ} \mathrm{C}$. Fig. 9 shows the results of the model (dashed line) with $C_{A M}=7.9 \pm 0.5 \mathrm{MPaK}^{-1} . C_{A M}$ determined by this method is close to $C_{A M}=$ $6.6 \pm 0.5 \mathrm{MPaK}^{-1}$ determined by using stress plateau.

The dependence on the temperature of the true storage evolution with true stress allows thus to determine Clausius-Clapeyron coefficient ; this method can be used in the absence of stress plateau, when the superelastic tensile tests are uniform.

\section{Conclusion}

The deformation mechanisms involved in the superelastic behavior of NiTi thin wires are still often explained by considering the tensile nominal stress-strain curve. In the usual 
presentation, four successive stages are distinguished during loading up to rupture. During the first stage, stress is considered as increasing linearly with strain, which is attributed to elastic deformation of austenite. The second stage is characterized by a stress plateau justified by the transformation from austenite to martensite. During the third stage, the stress is considered as increasing again linearly with strain which is explained by the elastic deformation of the oriented martensite. During the fourth stage, the slowdown of the stress increase is ascribed to martensite plasticity. The plateau stress during the second stage is considered as the transformation stress ; the Clausius Clapeyron coefficient is determined from the linear increase of this plateau stress with temperature.

In this paper, Dynamic Mechanical Analysis was used to measure storage moduli during superelastic tensile tests of NiTi thin wires as function of strain and stress at three temperatures above Af. The main conclusions are the following :

- during the first stage, nominal storage modulus $E^{\prime}$ is neither constant. Its continuous decrease with increasing strain is due to the occurrence of non elastic deformation mechanisms due to phase transformations $A-R, R-M$, and $A-M$

- during the third and fourth stages, continuous increase of the nominal storage modulus is due to deformation mechanisms other than elastic and plastic mechanisms, including phase transformation and twinning-detwinning phenomena,

- the evolution of the nominal storage modulus $E^{\prime}$ during the stress plateau is only due to the localization phenomenon as shown by a simple model proposed in this paper.

In this paper, it was shown that DMA results allows :

- to estimate the elastic modulus of austenite as the initial value at low stress of the nominal storage modulus during the first stage. Estimation is better for highest test temperature to reduce the effect of the $\mathrm{R}$ phase. With this method, elastic modulus of austenite $E_{A}$ is estimated equal to $70 \mathrm{GPa}$, independently of the test temperature.

- to estimate the elastic modulus of oriented martensite from the evolution of the storage modulus during the fourth stage, just before the rupture. In this high stress and strain ranges, it is mandatory to calculate the true storage modulus $E_{t}^{\prime}$ from the true strain and stress. The elastic modulus of oriented martensite $E_{M}$ is estimated as the asymptotic value of the true storage modulus $E_{t}^{\prime}$ during the last stage preceding the rupture. With this method, elastic modulus of oriented martensite $E_{M}$ is estimated equal to $73 \mathrm{GPa}$, slightly higher than the elastic modulus of the austenite.

- to propose a method to determine the Clausius Clapeyron coefficient $C_{A M}$ of the forward martensitic transformation without using the stress plateau stage characterized by localized deformation. This method is based on a model $E_{t}^{\prime}\left(\sigma_{t}, T_{0}\right)$ of the evolution of the true storage modulus $E_{t}^{\prime}$ as function of true stress $\sigma_{t}$ at a reference temperature $T_{0} . C_{A M}$ is the coefficient which allows to extent this model to other temperature $T$ under the form $E_{t}^{\prime}\left(\sigma_{t}, T\right)=E_{t}^{\prime}\left(\sigma_{t}-C_{A M}\left(T-T_{0}\right), T_{0}\right)$.

\section{Acknowledgement}

The authors wish to acknowledge the financial support of the ANR research program Guidage d'une Aiguille Médicale Instrumentée - Déformable (ANR12-TECS-0019). 


\section{References}

[1] K. Otsuka and X. Ren. Physical metallurgy of Ti-Ni-based shape memory alloys. Progress in Materials Science, 50(5):511-678, 2005.

[2] S. Besseghini, E. Villa, and J. Portman. DMA characterization of a Ni50.5at\%Ti shape memory alloys. International Journal of Applied Electromagnetics and Mechanics, 23(1-2):33-38, 2006.

[3] G. Fan, Y. Zhou, K. Otsuka, X. Ren, K. Nakamura, T. Ohba, T. Suzuki, I. Yoshida, and F. Yin. Effects of frequency, composition, hydrogen and twin boundary density on the internal friction of Ti50Ni50-xCux shape memory alloys. Acta Materialia, 54(19):5221-5229, 2006.

[4] T. Inamura, Y. Yamamoto, H. Y. Kim, K. Wakashima, S. Miyazaki,and H. Hosoda. Stress Amplitude Dependence of Internal Friction in TiNbAl Shape Memory Alloy. In T Chandra, $\mathrm{N}$ Wanderka, W Reimers, and M Ionescu, editors, THERMEC 2009, PTS 1-4, volume 638-642 of Materials Science Forum, pages 2064-2067. Minerals, Met \& Mat Soc, 2010.

[5] A. Nespoli, F. Passaretti, and E. Villa. Phase transition and mechanical damping properties: A DMTA study of NiTiCu shape memory alloys. Intermetallics, 32:394-400, 2013.

[6] R. Artiaga, A. Garcia, L. Garcia, A. Varela, J. L. Mier, S. Naya, and M. Grana. DMTA study of a nickel-titanium wire. Journal of Thermal Analysis and Calorimetry, 70(1):199-207, 2002.

[7] K. S. Suresh, D. Lahiri, A. Agarwal, and S. Suwas. Microstructure dependent elastic modulus variation in NiTi shape memory alloy. Journal of Alloys and Compounds, 633:7-74, 2015.

[8] J. Van Humbeeck. Damping capacity of thermoelastic martensite in shape memory alloys. Journal Of Alloys And Compounds, 355(1-2):58-64, 2003.

[9] Y. Liu and J. Van Humbeeck. On the damping behaviour of NiTi shape memory alloy. Journal de physique IV, 7(C5):519-524, November 1997.

[10] S.H. Chang and S.K. Wu. Internal friction of R-phase and B19' martensite in equiatomic TiNi shape memory alloy under isothermal conditions. Journal of Alloys and Compounds, 437(12):120-126, June 2007.

[11] I. Yoshida, D. Monma, and T. Ono. Damping characteristics of Ti50Ni47Fe3 alloy. Journal of Alloys and Compounds, 448(1-2):349-354, 2008.

[12] Y. Chen, H. C. Jiang, S. W. Liu, L. J. Rong, and X. Q. Zhao. Damping capacity of TiNi-based shape memory alloys. Journal of Alloys and Compounds, 482(1-2):151-154, 2009.

[13] D. Roy, V. Buravalla, P.D. Mangalgiri, S. Allegavi, and U. Ramamurty.Mechanical characterization of NiTi SMA wires using a dynamic mechanical analyzer. Materials Science and Engineering: A, 494(1-2):429-435, October 2008.

[14] O. T. Bruhns. 60 Years of Research in Plasticity The Contributions of Th. Lehmann and his Group. Procedia Engineering, 173(1):3-10, 2017. 
[15] P. Schlosser, D. Favier, H. Louche, and L. Orgas. Experimental Characterization of NiTi SMAs Thermomechanical Behaviour Using Temperature and Strain Full-Field Measurements. Advances in Science and Technology, 59:140-149, 2008.

[16] V. Delobelle, G. Chagnon, D. Favier, and T. Alonso. Study of electropulse heat treatment of cold worked NiTi wire: from uniform to localised tensile behaviour. Journal of Materials Processing Technology, 227:244-250, 2016.

[17] Y. Liu and H. Xiang. Apparent modulus of elasticity of near-equiatomic NiTi. Journal of Alloys and Compounds, 270(1-2):154-159, May 1998.

[18] D. Favier, H. Louche, P. Schlosser, L. Org_eas, P. Vacher, and L. Debove. Homogeneous and heterogeneous deformation mechanisms in an austenitic polycrystalline NiTi thin tube under tension. Investigation via temperature and strain fields measurements. Acta Materialia, 55(16):5310-5322, September 2007.

[19] K. L. Ng and Q. P. Sun. Stress-induced phase transformation and detwinning in NiTi polycrystalline shape memory alloy tubes. Mechanics of Materials, 38(1-2):41-56, 2006.

[20] M.L. Young, M.F.-X. Wagner, J. Frenzel, W.W. Schmahl, and G. Eggeler. Phase volume fractions and strain measurements in an Ultrafine-grained NiTi shape-memory alloy during tensile loading. Acta Materialia, 58(7):2344-2354, April 2010.

[21] S. Rajagopalan, a. L. Little, M. a. M. Bourke, and R. Vaidyanathan.Elastic modulus of shapememory NiTi from in situ neutron diffraction during macroscopic loading, instrumented indentation, and extensometry. Applied Physics Letters, 86(8):081901, 2005.

[22] S. Qiu, B. Clausen, S.a. Padula, R.D. Noebe, and R. Vaidyanathan. On elastic moduli and elastic anisotropy in polycrystalline martensitic NiTi. Acta Materialia, 59(13):5055-5066, August 2011.

[23] A. P. Stebner, D. W. Brown, and L. C. Brinson. Young's modulus evolution and texture-based elastic-inelastic strain partitioning during large uniaxial deformations of monoclinic nickeltitanium. Acta Materialia, 61(6):1944-1956, 2013.

[24] P. Sittner, L. Heller, J. Pilch, C. Curfs, T. Alonso, and D. Favier. Young's Modulus of Austenite and Martensite Phases in Superelastic NiTi Wires. Journal of Materials Engineering and Performance, 23(7):2303-2314, 2014.

[25] M. Thomasova, H. Seiner, P. Sedlak, M. Frost, M. Sevcik, I. Szurman, R. Kocich, J. Drahokoupil, P. Sittner, and M. Landa. Evolution of macroscopic elastic moduli of martensitic polycrystalline NiTi and NiTiCu shape memory alloys with pseudoplastic straining. Acta Materialia, 123:146-156, 2017.

[25bis] L. Heller, P. Šittner, P. Sedlák, H. Seiner, O. Tyc, and L. Kadeřávek, "Beyond the strain recoverability of martensitic transformation in NiTi," Int. J. Plast., vol. 116, no. October 2018, pp. 232-264, 2019. 
[26] D. Jiang, S. Kyriakides, C.M. Landis, and K. Kazinakis. Modeling of propagation of phase transformation fronts in NiTi under uniaxial. European Journal of Mechanics / A Solids, 2017. [27] J. Ortin and A. Planes. Thermodynamics of thermoelastic martensitic transformations. Acta Metallurgica, 37(5):1433-1441, 1989.

[28] https://confluentmedical.com/wp-content/uploads/2017/11/sm495 wire dataConverted_v2.pdf. Accessed 21 May 2018.

[29] A.N.Bucsek, H.M.Paranjape, and A.P Stebner. Myths and Truths of Nitinol Mechanics: Elasticity and Tension-Compression Asymmetry. Shap.Mem.Superelasticity (2016) 2:264271.

a)

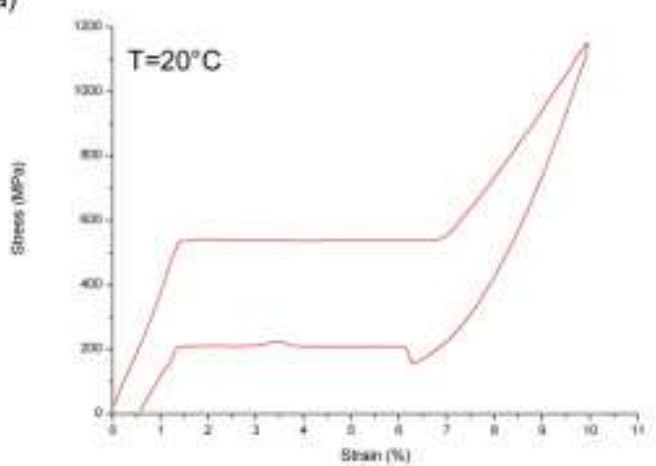

b)

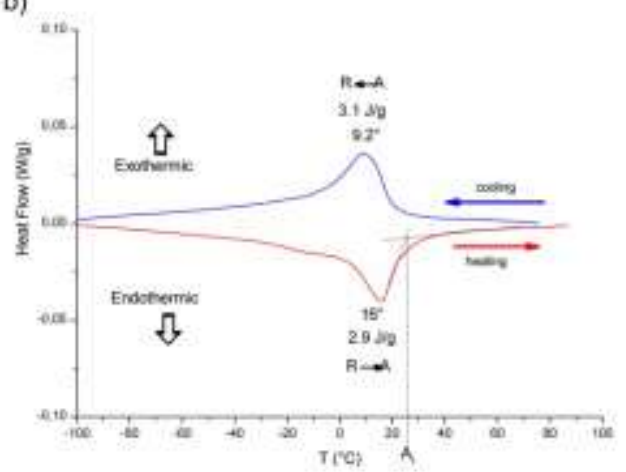

Fig.1 a) Nominal stress $\mathrm{F} / \mathrm{SO}$ versus nominal strain $\Delta \mathrm{L} / \mathrm{LO}$ for a tensile test at $\mathrm{T}=20^{\circ} \mathrm{C}$; b) Differential Scanning Calorimetry measurements.
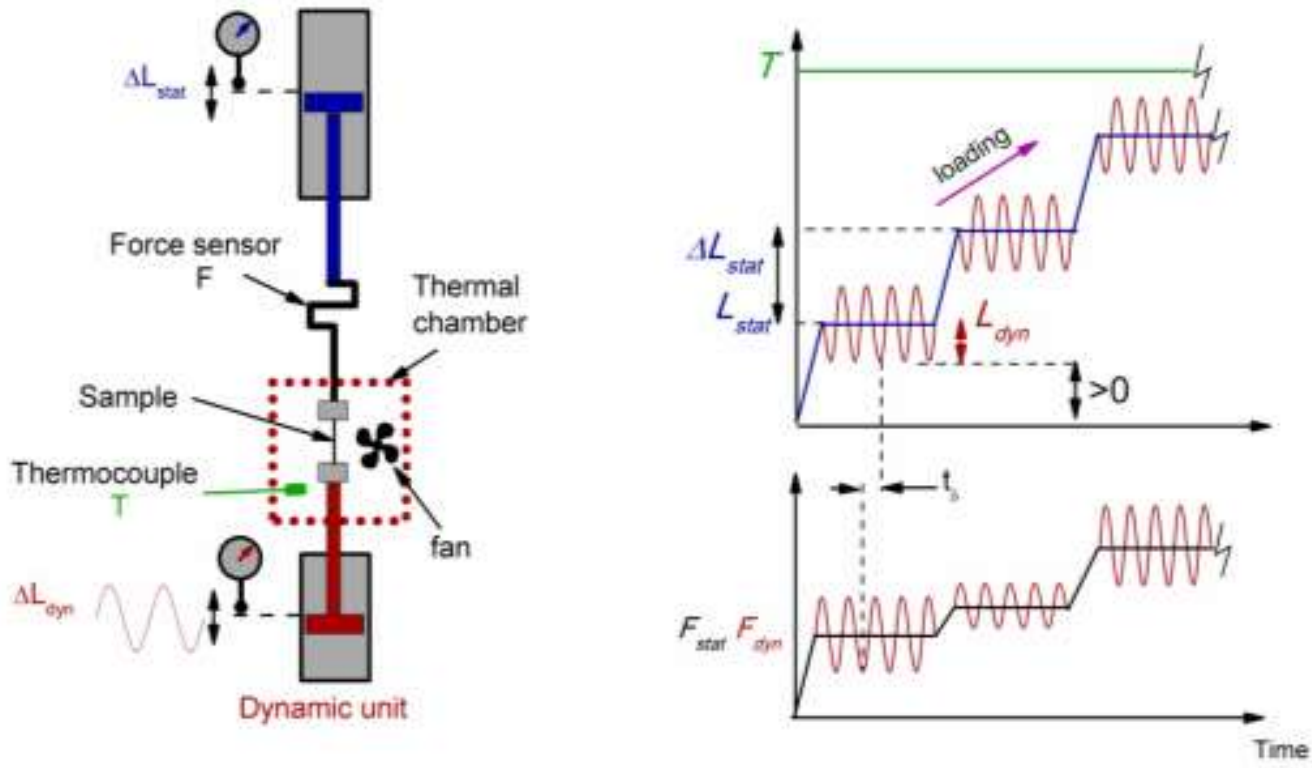

Fig. 2 a) Netzsch-Gabo Eplexor device, description of static and dynamic drives ; b) DMA and static sweep test (DMA-SS test). 


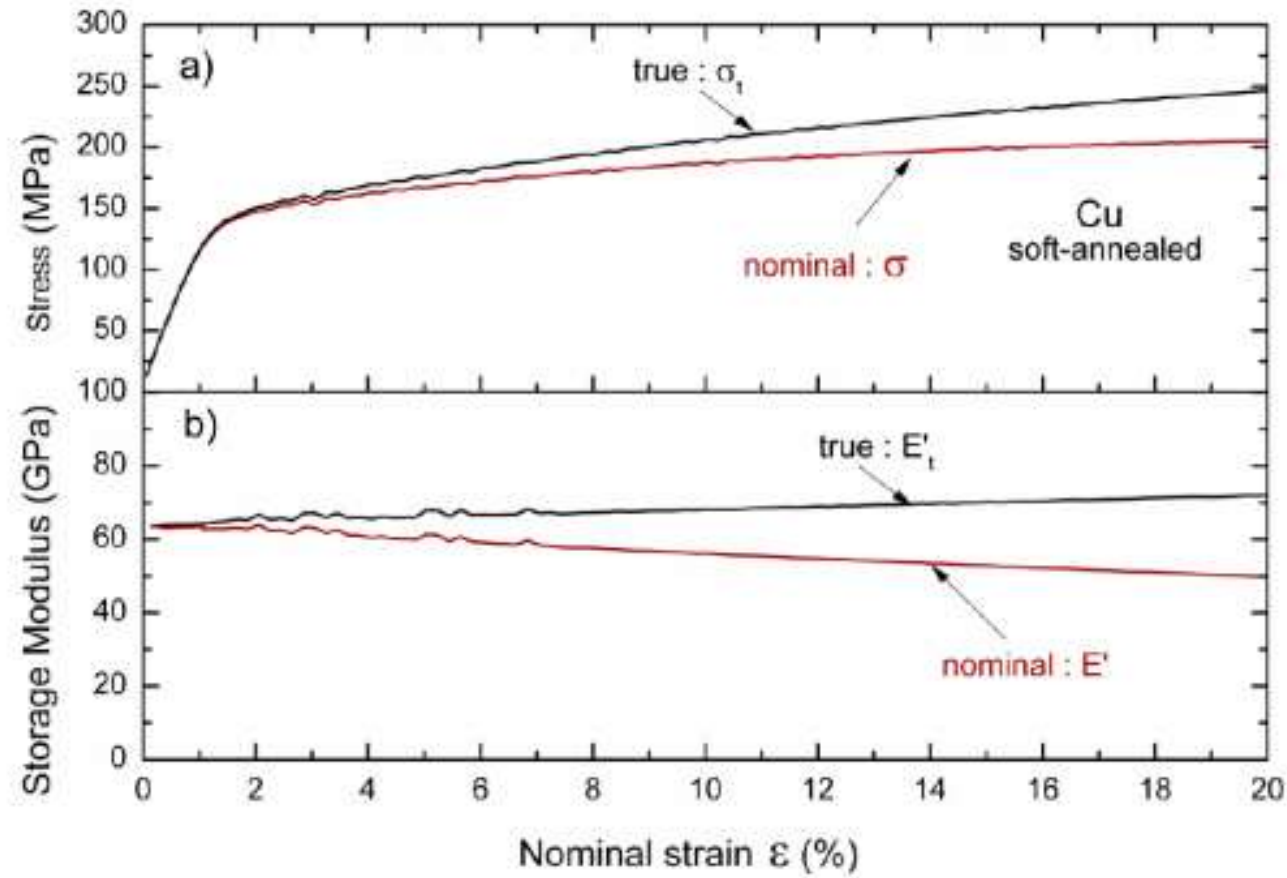

Fig. 3. DMA-SS test for a soft annealed Cu wire. a) Nominal and true stresses as function of the nominal strain; b) nominal and true storage moduli as function of the nominal strain.
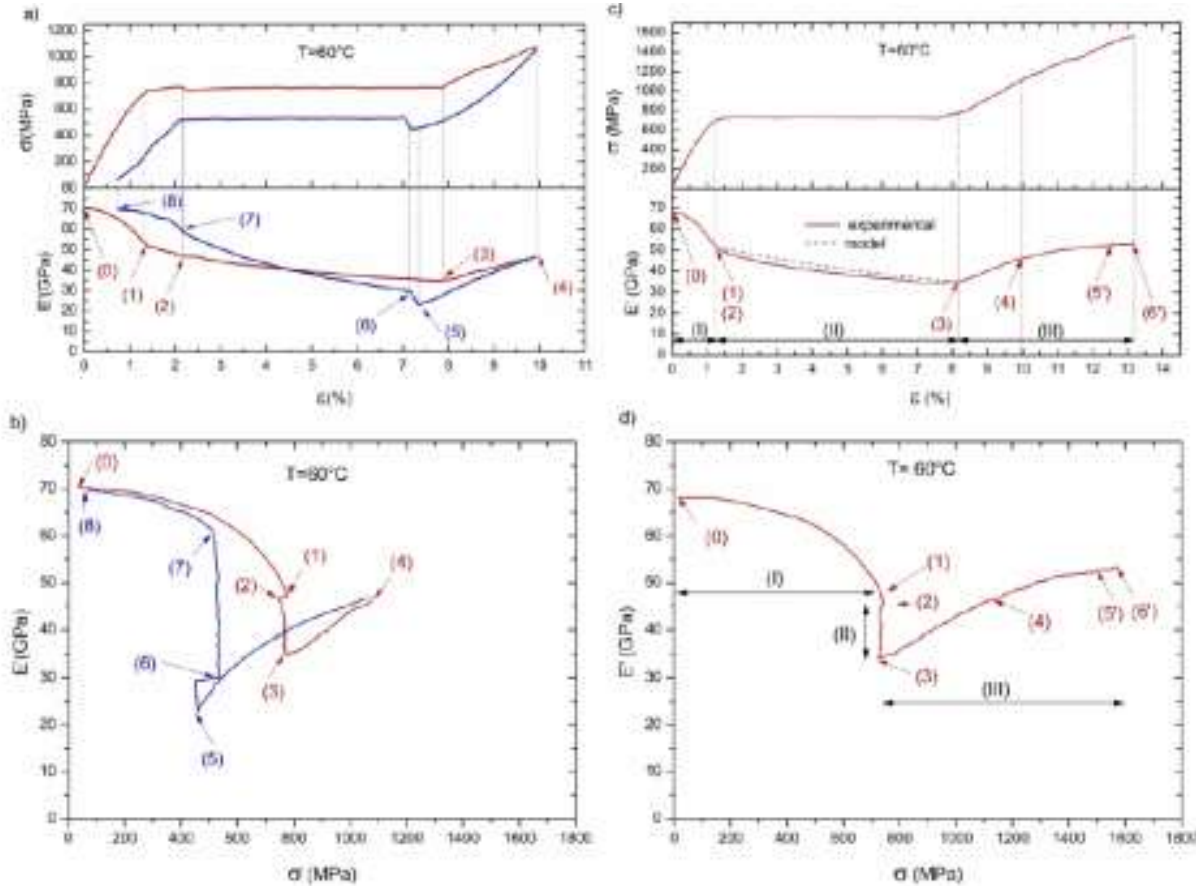

Fig. 4. DMA-SS test at $T=60^{\circ} \mathrm{C}$ a) nominal stress-strain and nominal storage modulus-strain for a loading/unloading ; b) nominal storage modulus-nominal stress for a loading/unloading; c) nominal stressstrain and nominal storage modulus-strain up to rupture; d) nominal storage modulus-nominal stress up to rupture. 

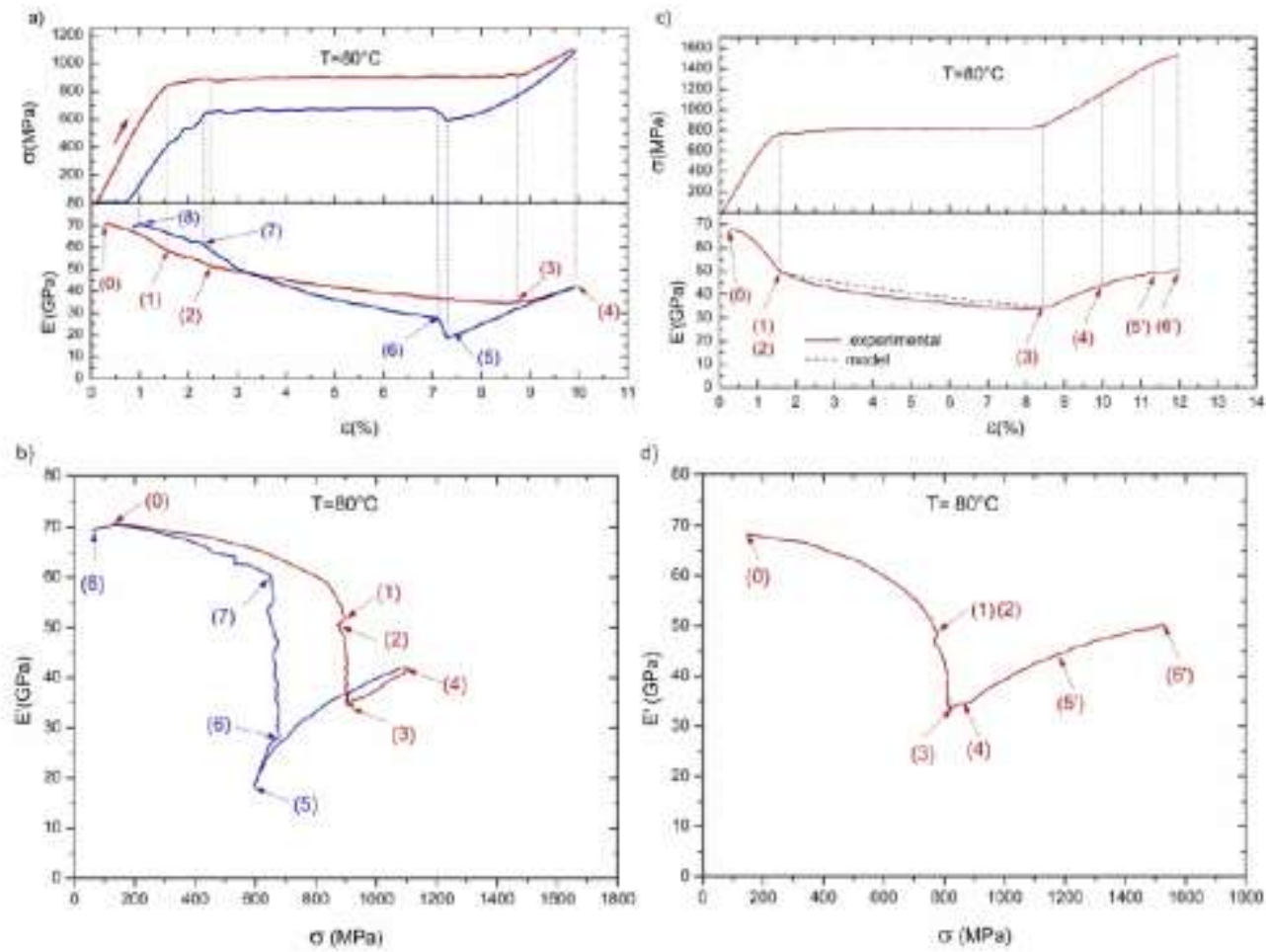

Fig. 5. DMA-SS test at $T=80^{\circ} \mathrm{C}$ a) nominal stress-strain and nominal storage modulus-strain for a loading/unloading, b) nominal storage modulus-stress for a loading/unloading, c) nominal stress-strain and nominal storage modulus-strain up to rupture, d) nominal storage modulus-stress up to rupture. 


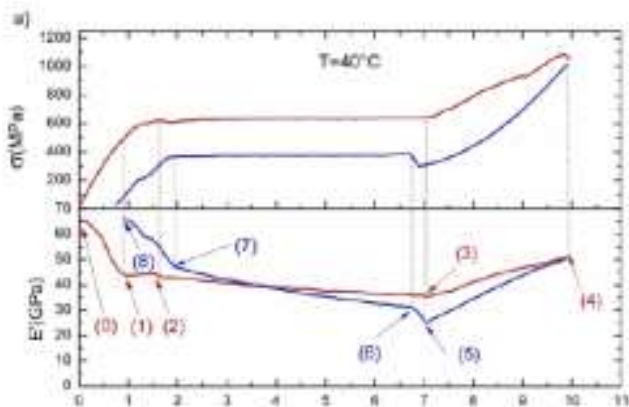

Kat

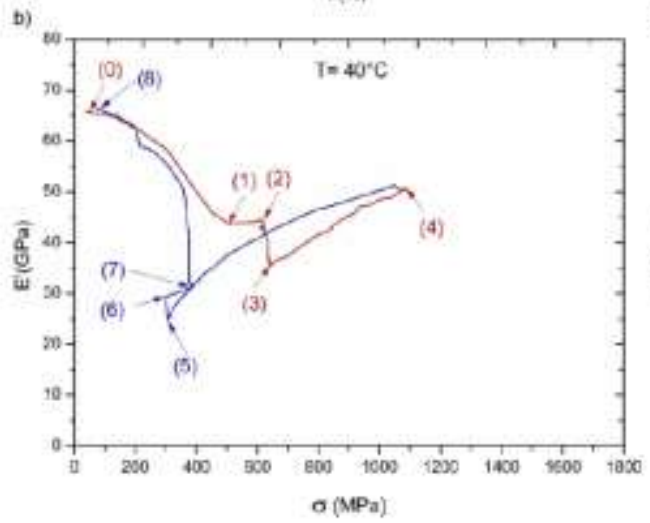

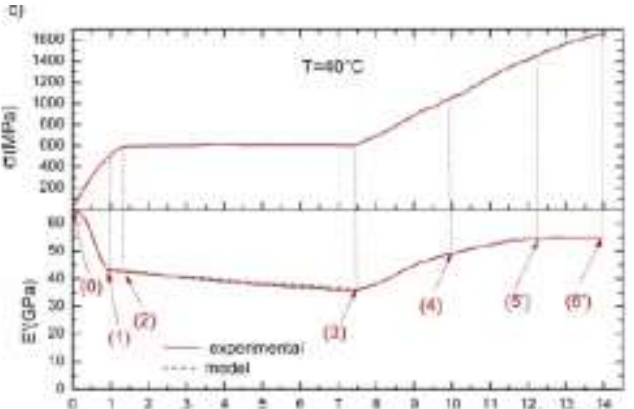

$B(15)$

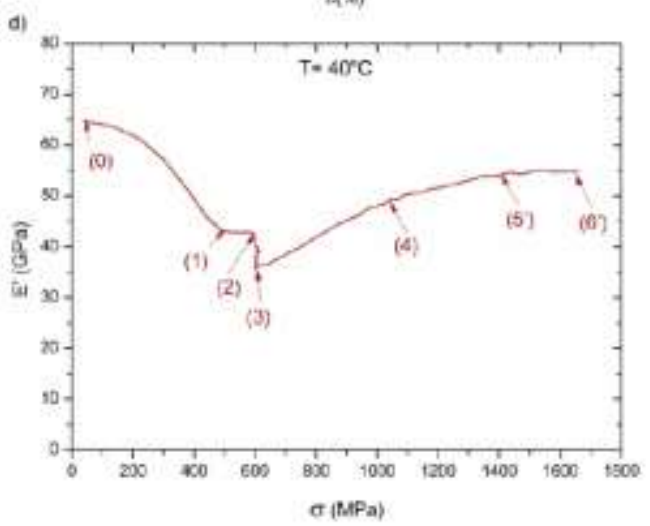

Fig. 6. DMA-SS test at $T=40^{\circ} \mathrm{C}$ a) nominal stress-strain and nominal storage modulus-strain for a loading/unloading, b) nominal storage modulus-stress for a loading/unloading,c) nominal stress-strain and nominal storage modulus-strain up to rupture, d) nominal storage modulus-stress up to rupture.
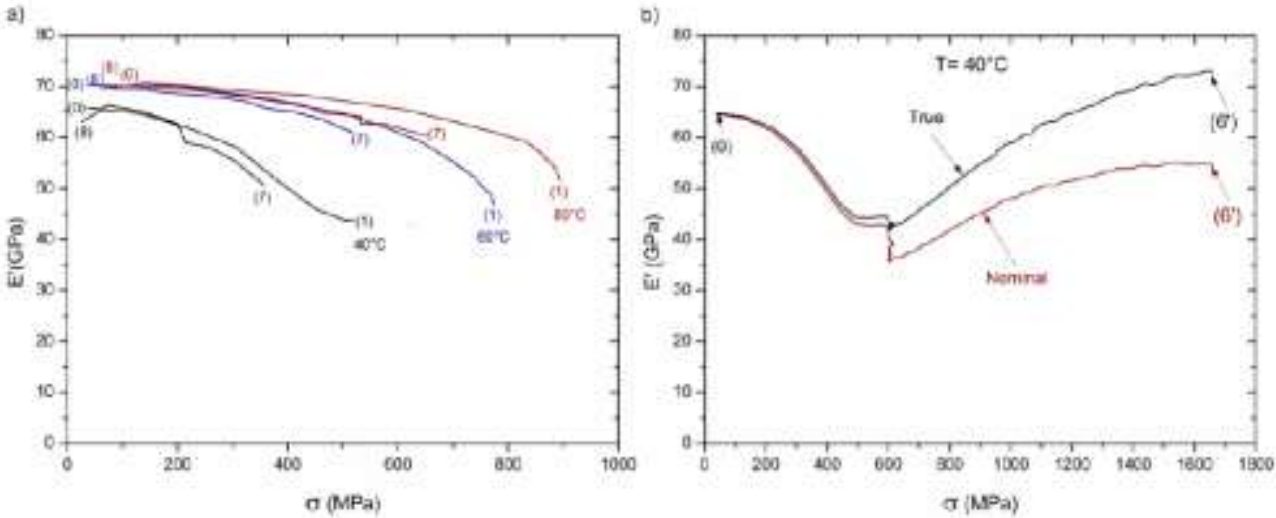

Fig. 7. a) Nominal storage modulus-stress between ( 0 ) and (1) and between (7) and (8) for $40^{\circ} \mathrm{C}, 60^{\circ} \mathrm{C}$ and $80^{\circ} \mathrm{C}$. b) Nominal and true storage modulus-stress between $(0)$ and $\left(6^{\prime}\right)$ for $T=40^{\circ} \mathrm{C}$ up to rupture. 


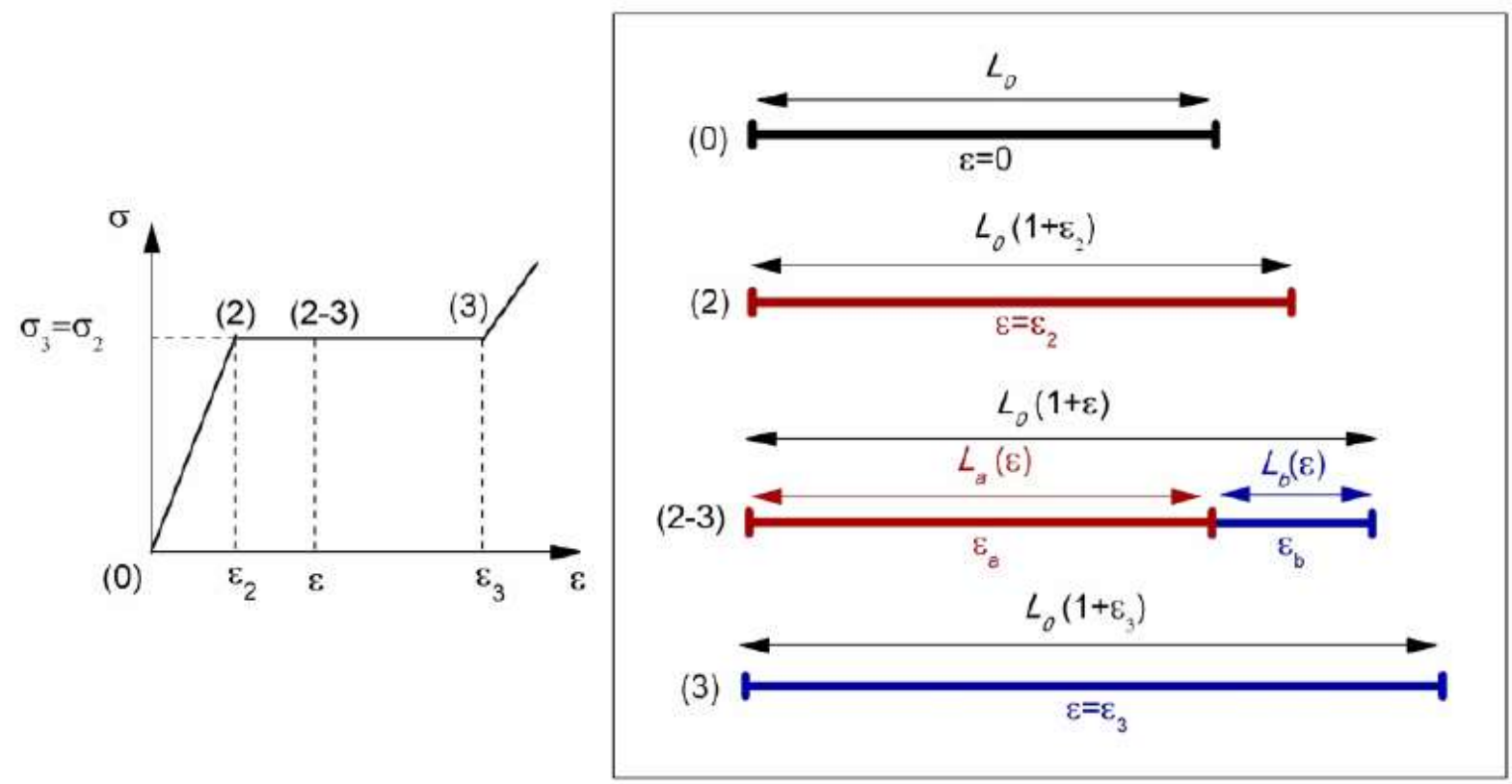

Fig. 8. Model of wire deformation during localization 


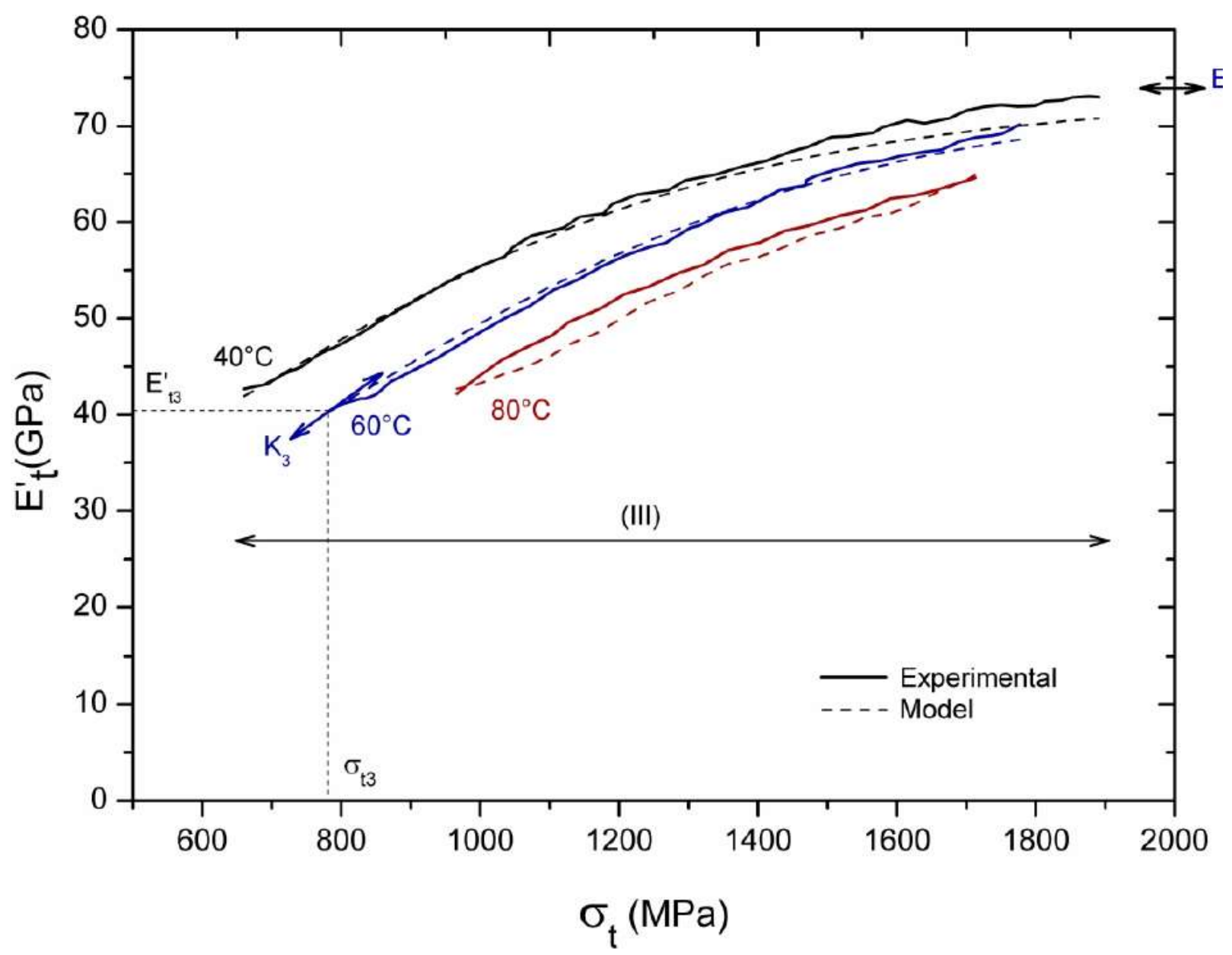

Fig. 9. True storage modulus-true stress of zone (III)- Experiments and model 
Table 1 : Identification of elasticity, plasticity, uniform and localized deformation phenomena from nominal stress-strain and storage modulus-strain evolutions during loading

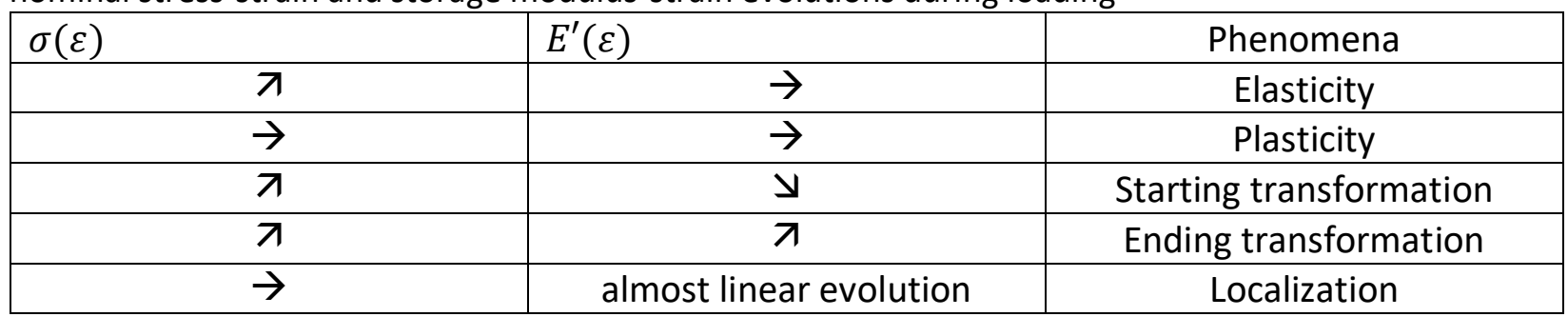

Table 2 : Values of the slopes $\frac{\Delta \sigma}{\Delta \varepsilon}$ and $\frac{\Delta \sigma_{t}}{\Delta \varepsilon_{t}}$ determined from the nominal stress-strain and true stressstrain curves, respectively. The points (0), (3) and (4) are defined in figures 6,4 and 5 for $T=40,60^{\circ} \mathrm{C}$ and $80^{\circ} \mathrm{C}$ successively. The slopes are calculated with a stress range $\Delta \sigma=200 \mathrm{MPa}$.

\begin{tabular}{|c|c|c|c|c|c|}
\hline & Point (0) & \multicolumn{2}{|c|}{ Loading in (3) } & \multicolumn{2}{c|}{ Unloading in (4) } \\
\hline Temperature & $\frac{\Delta \sigma}{\Delta \varepsilon}=\frac{\Delta \sigma_{t}}{\Delta \varepsilon_{t}}$ & $\frac{\Delta \sigma}{\Delta \varepsilon}$ & $\frac{\Delta \sigma_{t}}{\Delta \varepsilon_{t}}$ & $\frac{\Delta \sigma}{\Delta \varepsilon}$ & $\frac{\Delta \sigma_{t}}{\Delta \varepsilon_{t}}$ \\
\hline $40^{\circ} \mathrm{C}$ & $63 \mathrm{GPa}$ & $17 \mathrm{GPa}$ & $19 \mathrm{GPa}$ & $38 \mathrm{GPa}$ & $41 \mathrm{GPa}$ \\
\hline $60^{\circ} \mathrm{C}$ & $69 \mathrm{GPa}$ & $16 \mathrm{GPa}$ & $18 \mathrm{GPa}$ & $35 \mathrm{GPa}$ & $39 \mathrm{GPa}$ \\
\hline $80^{\circ} \mathrm{C}$ & $69 \mathrm{GPa}$ & $18 \mathrm{GPa}$ & $21 \mathrm{GPa}$ & $30 \mathrm{GPa}$ & $34 \mathrm{GPa}$ \\
\hline
\end{tabular}

Table 3 : Values of the nominal $E^{\prime}$ and true $E_{\mathrm{t}}^{\prime}$ storage moduli. The points (0), (4) and $\left(6^{\prime}\right)$ are defined in figures 6,4 and 5 for $\mathrm{T}=40,60^{\circ} \mathrm{C}$ and $80^{\circ} \mathrm{C}$ successively

\begin{tabular}{|c|c|c|c|c|c|}
\hline \multirow{2}{*}{ Temperature } & Point (0) & \multicolumn{2}{|c|}{ Loading and unloading in (4) } & \multicolumn{2}{c|}{ Loading in (6') } \\
\cline { 2 - 6 } & $E^{\prime}=E_{\mathrm{t}}^{\prime}$ & $E^{\prime}$ & $E_{\mathrm{t}}^{\prime}$ & $E^{\prime}$ & $E_{\mathrm{t}}^{\prime}$ \\
\hline $40^{\circ} \mathrm{C}$ & $66 \mathrm{GPa}$ & $50 \mathrm{GPa}$ & $62 \mathrm{GPa}$ & $55 \mathrm{GPa}$ & $73 \mathrm{GPa}$ \\
\hline $60^{\circ} \mathrm{C}$ & $70 \mathrm{GPa}$ & $47 \mathrm{GPa}$ & $58 \mathrm{GPa}$ & $53 \mathrm{GPa}$ & $70 \mathrm{GPa}$ \\
\hline $80^{\circ} \mathrm{C}$ & $71 \mathrm{GPa}$ & $42 \mathrm{GPa}$ & $52 \mathrm{GPa}$ & $50 \mathrm{GPa}$ & $70 \mathrm{GPa}$ \\
\hline
\end{tabular}

